\title{
Antrenör Kişilerarası Davranış Tarzı Ölçeği: Geçerlik-Güvenirlik Çalışması
}

\section{Coaches'Interpersonal Style Questionnaire: Validity And Reliability Study}

\author{
ORİJINAL ARASTTIRMA/ \\ ORIGINAL RESEARCH
}

Oğuz Kaan ESENTÜRK ${ }^{1 \dagger}$

${ }^{1}$ Erzincan Binali Yıldırım Üniversitesi, Eğitim Fakültesi, Beden Eğitimi ve Spor Öğretmenliği Bölümü, Erzincan https://orcid.org/0000-0002-0566-838X
$\ddot{O} z$

Bu araştırmanın amacı Antrenör Kişilerarası Davranış Tarzı Ölçeği’nin Türk kültürüne uyarlanmasıdır. Tarama modelinde desenlenen bu araştırmaya farklı spor branşlarında (futbol, basketbol, hentbol, rugby) lisanslı olarak aktif spor yapan ve yaşları 17-32 arasında değişen 124'ü erkek 98'i kadın toplam 212 sporcu gönüllü olarak katılmıştır. Verilerin analizi için Spss ve AMOS 22 paket programları kullanılmıştır. Araştırmada ilk olarak ölçme aracının geçerliği kapsamında Doğrulayıcı Faktör Analizi (ConfirmatoryFactor Analysis) yapılmıştır. Araştırmada DFA sonucunda ortaya çıkan faktör yapısının örneklem grubundan elde edilen veriler ile doğrulandığı belirlenmiştir. Madde-toplam test korelasyon değerlerinin 0.27 ile 0.93 arasında değiştiği görülmektedir. Toplam puana göre üst $\% 27$ ve alt \% 27'lik grupların madde puanları arasındaki farkın anlamlılığı için t-testi incelendiğinde, $t$ değerlerinin 9.77 (sd: 103, $\mathrm{p}<0.01$ ) ile 17.29 (sd: 103, p<0.01) arasında değiştiği görülmektedir. Ölçme aracının Cronbach Alpha güvenirlik değerleri "Özerklik Destekleme " alt boyutunda 0.80, "Yeterlilik Desteği” alt boyutunda 0.88, "İlişki Desteği” alt boyutunda 0,93, "Özerkliği Engelleme" alt boyutunda 0.73, "Yeterlilik Engelleme" alt boyutunda 0.89 ve "İlişki Engelleme" alt boyutunda ise 0,88 olarak tespit edilmiştir.Bu bulgular 1 șığında, Antrenör Kişilerarası Davranış Tarzı Ölçeği'nin (AKDTÖ) geçerli ve güvenilir ölçümler yapabilen bir veri toplama aracı olduğu söylenebilir.

Anahtar Kelimeler: Antrenör Kişilerarası Davranış Tarzı, Geçerlik, Güvenirlik

\begin{abstract}
The aim of this study was to adaptthe Coaches' Interpersonal Style Questionnaire to Turkish culture. A total of 212 athletes, 124 malesand 98 females, aged between 17-32, engaged in actives ports with different licenses (football, basketball, handball, rugby) and participated in this study, which was designed in the screening model, voluntarily. Spss and AMOS 22 software were used for data analysis. First of all, Confirmatory Factor Analysis was conducted within the scope of the validity of the measurement tool. In the study, it wa sdetermined that the factor structure that was obtained as a result of CFA was confirmed with the data obtained from the sample group. Item-total test correlation values vary between 0.27 and 0.93 . When the t-test was examined for the significance of the difference between the item scores of the upper $27 \%$ and lower $27 \%$ according to the total score, $t$ values were 9.77 (sd: 103, p<0.01) and 17.29 (sd): 103, $\mathrm{p}<0.01$ ). It was found to be the Cronbach's alpha reliability values of the measurement tool were 0.80 in the "Autonmy Support"sub-dimension, 0.88 in the "Competence Support "sub-dimension, 0.93 in the" Relatedness Support"sub-dimension, 0.73 in the "Autonomy Thwarting"sub-dimension, 0.89 in the "Competence Thwarting" and 0,88 in the "Relatedness Thwarting". In the light of these findings, it can be said that the Coaches' Interpersonal Style Questionnaire is a measurement tool that can make validity and reliable measurements.
\end{abstract}

Keywords: Coaches' Interpersonal Style, Validity, Reliability

\footnotetext{
+ Sorumlu yazar: Oğuz Kağan Esentürk, esenturk954@gmail.com
} 


\section{GİRIŞ}

Spor bağlamında genç sporcuların gelişimi üzerinde antrenörler, ebeveynler veya takım arkadaşları da dahil olmak üzere farklı faktörler söz sahibi olabilmektedir (Adie, Duda ve Ntoumanis, 2012). Özellikle antrenörlerin davranışları ve takım içindeki rolleri, bir aktivitenin gerçekleştirilmesinin olumlu veya olumsuz sonuçlarını belirleyebilmektedir (Curran, Hill ve Niemiec, 2013). Ehsani ve diğerlerine göre (2012), sporcuları etkileyebilecek en önemli faktörlerden biri antrenör davranışlarıdır. Sporcular antrenörleri ile her antrenman aşamasında ve müsabakalarda etkileşime girerler. İlaveten, antrenörler sporcu için bir rol model olabilir ve aynı zamanda sporcuların spor dışındaki hayatı üzerinde de etki yaratabilecek insanlardan birisidir. Yapılan araştırmalarda istenmeyen antrenör davranışlarının spor doyumu ve tükenmişlikle ilgili olumsuz sonuçlara yol açabileceği belirtilmektedir (Fraser-Thomas ve Côté, 2009; Gould, Tuffey, Udry ve Loehr,1996). Ayrıca bazı araştırmacılar, antrenörlerin kişilerarası davranış tarzlarının sporcuların motivasyonu için önemli olduğunu ifade etmişlerdir (Adie, Duda ve Ntoumanis, 2012; Balaguer ve ark., 2012).

Deci ve Ryan (1985), sporcuların motivasyonel ihtiyaçlarını karşılamak için bir dizi sosyal faktörün gerekli olduğunu ifade etmektedir. Spor içinde bu faktörlerden birisi antrenörlerin sosyalleşme etkilerini ileten ve sporcuya katılım ya da hoşnutsuzluk gibi duygusal sonuçları olan bir ortam yaratan kişilerarası davranış tarzlarıdır (Ryan ve Deci, 2000). Antrenörlerin kişilerarası davranış tarzları, ya psikolojik ihtiyaç memnuniyetini destekleyen bir öğrenme ortamı benimsemeyi ya da hayal kırıklığı duyguları üreten engelleyici davranışları seçmeyi içerir (Pulido, Sánchez-Oliva, Leo, Matos ve García-Calvo). Ancak antrenörler, genellikle sporcuların özerkliğini engelleyen yönerge ve korkutucu davranışların sık kullanımına başvurabilir (Reeve, 2000). Bu durum sporcuların performasını olumsuz yönde etkilemekle birlikte, antrenör sporcu ilişsisinde de bazı problemler yaratabilmektedir. Dolayısıyla antrenörlerin sporculara yönelik davranış tarzları performans anlamında belirleyici rol oynamaktadır.

Ulusal literatür incelendiğinde, antrenörlerin kişilerarası davranış tarzlarını ölçen herhangi bir ölçme aracına rastlanılmamıştır. Bu araştırma ile antrenörlerin kişilerarası davranış stillerinin ortaya çıkarılması önemli görülmektedir. Bu araştırmanın amacı Antrenör Kişilerarası Davranış Tarzı Ölçeği’nin Türk kültürüne uyarlanmasıdır. 


\section{YÖNTEM}

\section{Katılımcilar}

Araştırmaya farklı spor branşlarında (futbol, basketbol, hentbol, rugby) lisanslı olarak aktif spor yapan ve yaşları 17-32 arasında değişen 124'ü erkek 98'i kadın toplam 212 sporcu gönüllü olarak katılmıştır.

\section{Veri Toplama Aracı}

Antrenör Kişilerarası Davranış Tarzı Ölçeği (AKDTÖ), oyuncuların antrenörlerinin kişilerarası davranış tarzlarına ilişsin algılarını değerlendirmek için kullanılmaktadır. Ölçek, "Uygulama sırasında koçumuz..... " şeklinde ifade edilen 22 maddeden oluşmaktadır. Bu 22 maddelik araç altı alt boyuttan oluşmaktadır: Özerklik Destekleme, Yeterlilik Desteği, İlişki Desteği, Özerkliği Engelleme, Yeterlilik Engelleme ve İlişki Engelleme. Bu 22 maddelik ölçme aracı, antrenörlerinin destekleyici ve engelleyici davranışlarını oyuncuların nasıl algıladıklarını değerlendirmek için tasarlanmıştır. Tüm yanıtlar 1 (kesinlikle katılmıyorum) ile 5 (kesinlikle katılıyorum) arasında değişen 5 puanlık bir ölçekte derecelendirilmiştir.

\section{Verilerin Analizi}

Verilerin analizi için Spss ve AMOS 22 paket programları kullanılmıştır. Çalışmada ilk olarak analizlerin uygunluğu ve varsayımların kontrolü için boş verilerin değerlendirilmesi, normallik testi ve uç değerlerin belirlenmesi işlemleri yapılmıştır. Bu işlemler sonucunda, araştırmaya katılan toplam 212 sporcudan gelen yanıtlar doğrultusunda ölçeğin geçerlik ve güvenirlik çalışmaları yapılmıştır. Öncelikle ölçme aracının geçerliği kapsamında Doğrulayıcı Faktör Analizi (Confirmatory Factor Analysis) yapılmıştır. Madde analizleri doğrultusunda ise, madde toplam test korelasyonu ve \%27 alt-üst grup karşılaştırmalarına yer verilmiş̧ir. Ölçme aracının güvenirliğinde Cronbach Alpha testi kullanılmıştır. 


\section{BULGULAR}

Bu bölümde “Antrenör Kişilerarası Davranış Tarzı Ölçeği”nin geçerlik ve güvenirliğine kanıt sağlamak amacıyla yapılan istatistiksel analizler sunulmuştur.

\section{GEÇERLIK}

Dil Geçerliği: AKDTÖ’nün Türkçe’ye çevrilmesi ve uyarlanmasının yapılması için ilk olarak ölçeğin yazarından izin alınmıştır. Bu araştırma kapsamında Brislin (1986) tarafından önerilen standart çeviri-geri çeviri (back translation) yöntemi kullanılmıştır. Ölçeğin İngilizce orijinali, önce araştırmacılar tarafından daha sonra da akademik olarak İngilizce eğitim görmüş bir uzman, İngilizce bilen ve farklı takımlar milli takımlar seviyesinde antrenörlük yapan üç kişi tarafından incelenip Türkçeye çevrilmiştir. Elde edilen ölçekteki maddeler birbiri ile karşılaştırılmış ve aynı çeviriye sahip maddeler belirlenmiştir. Aynı çeviriye sahip maddeler ve farklı çeviriye sahip maddelerin her bir çeviri şekli yeniden farklı uzmanlara verilerek tekrar İngilizceye çevrilmiştir. Geri çevirisi yapılan ölçek maddeleri, orijinal ölçek maddeleri ile karşılaştırılmış; bu kapsamda farklılıklar ve hatalar tespit edilmiştir. İngilizce çeviri orijinal ölçek ile karşılaştırılarak birbirine en yakın çeviriler ile Türkçe ölçek son şeklini almıştır.

\section{Yapı Geçerliği}

AKDTÖ’nün Türk kültürüne uyarlanması sürecinde öncelikle yapı geçerliğinin sağlanılmasına çalışılmıştır. Ölçme aracının ölçmeye çalıştığı teorik yapıyı ölçebilme derecesi olarak tanımlanan yapı geçerliği ölçekte yer alan her bir maddenin birbiri ile olan ilişkisini ortaya koyar (Seçer, 2015). Hazırlanan bu ölçekteki maddelerin ölçülmek istenen yapıyı ne derece ölçtüğü sorunu yapı geçerliği ile ilgilidir. AKDTÖ’den elde edilen ölçümlerin yapı geçerliğini test etmek amacıyla doğrulayıcı faktör analizi uygulanmıştır.

Ölçme aracının teorik modelinin yapı geçerliğini değerlendirmek için DFA'dan yararlanılmıştır (Kline, 2005). Kültürlerarası ölçek uyarlama çalışmalarında ölçme aracının hedef kültürdeki faktör deseni için doğrudan DFA ile başlanması önerilebilir. Çünkü söz konusu aracın orijinal kültürdeki faktör deseni pek çok nitel ve nicel çalışmalarla ortaya konmuş ve aracın yapı geçerliliğine ilişkin deneysel kanıtlar belirlenmiştir. Böyle bir durumda söz konusu aracın faktör deseninde hedef kültürde korunup korunmadığı DFA ile test edilebilir. Yapılacak olan DFA'da aracın orijinal faktör desenine ilişkin model doğrulanmıyor ya da yüksek uyum indeksleri 
vermiyor ise bu durumda açıklayıcı faktör analizi ile hedef kültürdeki faktör deseninin keşfedilmesi yoluna gidilebilir (Çokluk, Şekercioğlu ve Büyüköztürk, 2010).

DFA sonucunda ölçme aracının 12. maddesi için anlamlı $\mathrm{t}$ değeri elde edilememiş ve bu maddeye ait hata varyansının da (0.86) yüksek olduğu belirlenmiştir. Ayrıca 12. maddenin ilgili boyuttaki faktör yükünün (0.26) düşük olması nedeniyle ölçme aracından çıarılmasına karar verilmiştir. Kline (2010) .30 civarındaki standartlaştırılmış ağıllıkların orta; .50 ve üzerindeki ağırlıkların ise büyük etki büyüklüklerini yansıttığını belirtmektedir. Nitekim DFA sonucunda 12. maddeye ilişkin elde edilen madde faktör yükünün düşük etki büyüklüğüne sahip olduğu ve ölçme aracından çıkarılmasının uygun olacağı görülmektedir.

Ölçek uyarlama çalışmalarında DFA'da sınanan modelin yeterliliğini ortaya koymak üzere pek çok uyum indeksi kullanılmaktadır (Büyüköztürk, Akgün, Kahveci ve Demirel, 2004). Bunlar içinde en sık kullanılanları Ki-Kare Uyum Testi (Chi- Square Goodness), iyilik uyum indeksi (Goodness of Fit Index, GFI) düzeltilmiş iyilik uyum indeksi (Adjustment Goodness of Fit Index, AGFI), karşılaştırmalı uyum indeksi (Comparative Fit Index, CFI), normlaştırılmış uyum indeksi (NFI), fazlalık uyum indeksi (Incremental Fit Index, IFI), tahmin hatalarının ortalamasının karekökü (Root Mean Square Error of Approximation. RMSEA), sıkı normlaştırılmış uyum indeksi (Parsimony Normed Fit Index. PNFI) ve sıkı iyilik uyum indeksi (Parsimony Goodness of Fit Index. PGFI) incelenmiştir. İlgili literatür doğrultusunda (Sümer, 2000; Schermelleh-Engel ve Moosbrugger, 2003; Kline, 2005; Tabachnick ve Fidell, 2007; Thompson, 2004; Jöreskog ve Sörbom, 1993; Schumacher ve Lomax, 1996; Hooper, Coughlan ve Mullen, 2008; Brown, 2006) uyum indekslerine ilişkin kabul edilebilir ve iyi varsayılan değer aralıkları ile birlikte 12. madde çıkarılmadan önceki değerler (DFA I) ve çıkarıldıktan sonra elde edilen değerler (DFA II) Tablo 1'de verilmiştir.

Tablo 1. Doğrulayıcı faktör analizine ilişkin elde edilen sonuçlar

\begin{tabular}{ccccc}
\hline Model Uyum İndeks & Mükemmel Aralık & Kabul Edilebilir Aralık & DFA I & DFA II \\
\hline $\mathrm{X}^{2} / \mathrm{sd}$ & $0<\mathrm{X}^{2} / \mathrm{sd}<2$ & $2<\mathrm{X}^{2} / \mathrm{sd}<3$ & 3.21 & 2.161 \\
\hline RMSEA & $0.00<\mathrm{RMSEA}<0.05$ & $0.05<\mathrm{RMSEA}<0.10$ & 0.083 & 0.074 \\
\hline PGFI & $0.95<\mathrm{PGFI}<1.00$ & $0.50<\mathrm{PGFI}<0.95$ & 0.645 & 0.74 \\
\hline PNFI & $0.95<\mathrm{PNFI}<1.00$ & $0.50<\mathrm{PNFI}<0.95$ & 0.729 & 0.78 \\
\hline GFI & $0.90<\mathrm{GFI}<1.00$ & $0.85<\mathrm{GFI}<0.90$ & 0.841 & 0.862 \\
\hline AGFI & $0.90<\mathrm{AGFI}<1.00$ & $0.85<\mathrm{AGFI}<0.90$ & 0.83 & 0.852 \\
\hline CFI & $0.95<\mathrm{CFI}<1.00$ & $0.90<\mathrm{CFI}<0.95$ & 0.90 & 0.935 \\
\hline
\end{tabular}


Tablo 1' de madde çıkarılmadan önceki $X^{2} /$ sd değerinin 3.21 olduğu görülmüştür. Diğer uyum indeksleri incelendiğinde; RMSEA $=0.083$, PGFI $=0.645$, GFI $=0.841$, AGFI $=0.83$, PNFI $=0.729$ ve $\mathrm{CFI}=0.90$ olarak tespit edilmiştir. 12 . madde çıkarıldıktan sonra $\mathrm{X}^{2} / \mathrm{sd}$ değerinin düştüğü ve diğer uyum indekslerinde faktör yapısının doğrulanması açısından olumlu değişmeler gerçekleştiği görülmüştür.Bu uyum indeksi değerlerinin bütünü göz önüne alındığında, ölçeğin Türkçe formunun orijinal ölçekle mükemmel uyum vermediği ancak kabul edilebilir düzeyde iyi uyum verdiği söylenebilir.

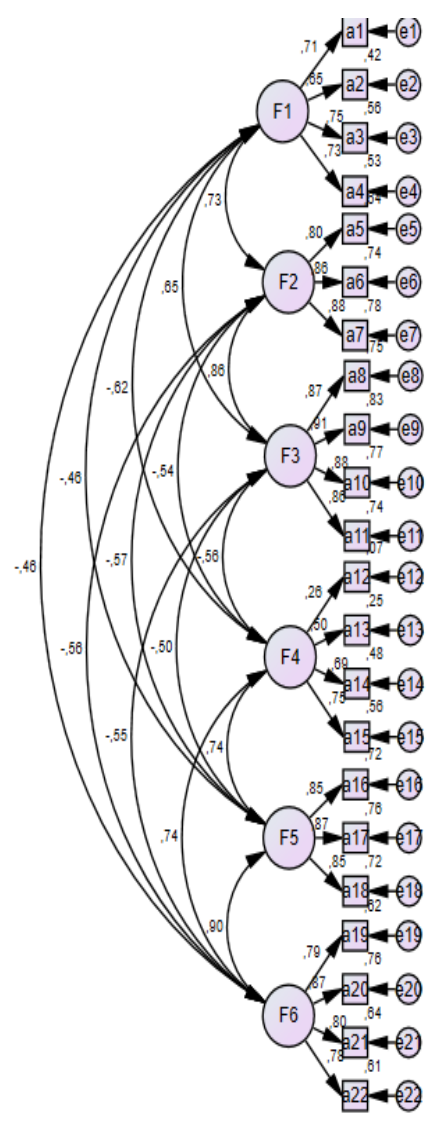

DFA I

F1: Özerklik Destekleme F4: Özerkliği Engelleme

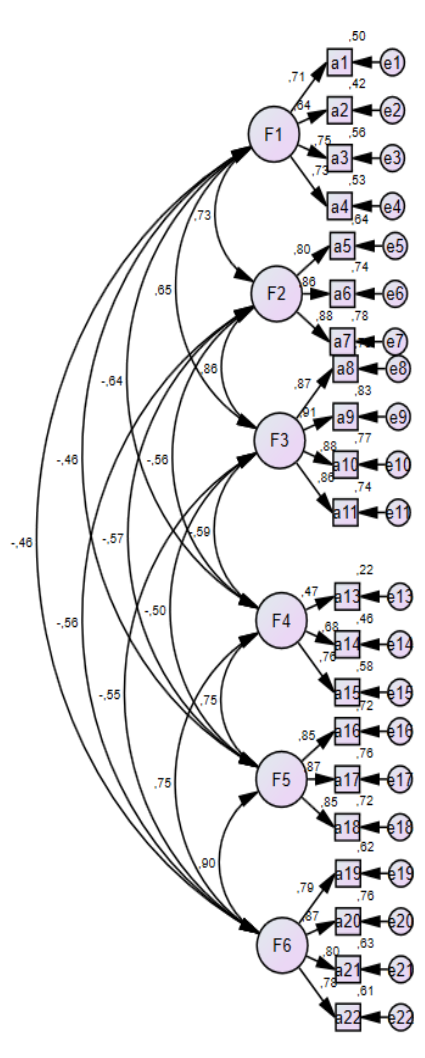

DFA II

Şekil 1. Antrenör Kişilerarası Davranış Tarzı Ölçeği DFA Sonuçları

DFA sonucunda elde edilen 6 boyutlu modele ilişkin faktör yükleri Şekil 2'de yer almaktadır. Şekil 1, 12. maddenin çıkarıldığı modelde (DFA II) yer alan tüm maddelerin yüksek faktör yüklerine sahip olduklarını göstermektedir. 


\section{Madde analizleri}

AKDTÖ'den elde edilen verilerin madde analizleri, madde toplam test korelasyonu ve \% 27 alt-üst grupları karşılaştırılarak incelenmiştir. Madde analizine ilişkin bulgular Tablo 3'de sunulmuştur. Ölçekte yer alan her bir maddenin ölçmek istediği özelliği ölçüp ölçmediği ve ölçtükleri özellik açısından kişileri ayırt etmede ne kadar yeterli olduklarının belirlenmesi amacıyla ilk olarak madde-toplam test korelasyonları hesaplanmıştır. Eğer bir maddenin toplam puanla olan korelasyonu düşük ise bu durum o maddenin testteki diğer maddelerden farklı bir niteliği ölçtüğünü gösterir (Karasar, 2014). Uzmanlar madde-toplam test korelasyonu 0.30 ve daha yüksek olan maddelerin iyi derecede ayırt edicilik özelliğe sahip olduğunu belirtmektedir (Erkuş, 2014). Madde toplam test korelasyonu test maddelerinden alınan puanlar ile testin toplam puanı arasındaki ilişkiyi açıklamaktadır. Madde-toplam korelasyonunun pozitif ve yüksek olmasının maddelerin benzer davranışları örneklediğini ve testin iç tutarlılığının yüksek olduğunu göstermektedir (Büyüköztürk, Akgün, Kahveci ve Demirel, 2004).

Tablo 2 incelendiğinde, madde-toplam test korelasyon değerlerinin 0.27 ile 0.93 arasında değiştiği görülmektedir. Bu durum 12. madde dışında her bir maddenin ölçeğin tamamıyla ilişkili ve uyum içinde olduğu şeklinde ifade edilebilir. Her bir maddenin ölçülmek istenen özelliğe sahip olan bireylerle olmayanları ayırt edip etmediği, toplam ölçek puanlarına göre belirlenmiş olan üst \% 27 (ölçülen özelliğe yüksek düzeyde sahip olduğu varsayılan) ve alt \% 27 (ölçülen özelliğe düşük düzeyde veya sahip olmadığı varsayılan) grubun ortalama puanları arasındaki farklar bağımsız t-testi ile incelenmiştir. Tablo 3'de toplam puana göre üst $\% 27$ ve alt \% 27'lik grupların madde puanları arasındaki farkın anlamlılığı için t-testi (Çakmak, Çebi ve Kan, 2014) incelendiğinde, t değerlerinin 9.77 (sd: 103, p<0.01) ile 17.29 (sd: 103, p<0.01) arasında değiştiği görülmektedir. Alt ve üst grup arasındaki farklara ilişkin $t$ değerlerinin anlamlı olması maddenin ayırt ediciliği için bir kanıt olarak değerlendirilmektedir (Erkuş, 2014). 

ve Spor Bilimleri Dergisi, 14 (2), 304-314.

Tablo 2. AKDTÖ'ye ilişkin madde analizi sonuçları

\begin{tabular}{lcccr}
\hline No & $\begin{array}{r}\text { Düzeltilmiş Madde } \\
\text { Toplam Test Korelasyonu }\end{array}$ & $\begin{array}{c}\text { \% 27 Alt-Üst Grup } \\
\text { Karşlaştırması }(\mathrm{t})\end{array}$ & Ort (X) & Ss \\
\hline 1 & $.803^{* *}$ & $16.26^{* * *}$ & 3.28 & 1.16 \\
2 & $.733^{* *}$ & $10.31^{* *}$ & 3.77 & .98 \\
3 & $.813^{* *}$ & $18.89^{* *}$ & 3.27 & 1.13 \\
4 & $.810^{* *}$ & $17.294^{* *}$ & 3.37 & 1.14 \\
5 & $.872^{* *}$ & $15.25^{* *}$ & 3.96 & .95 \\
6 & $.916^{* *}$ & $13.82^{* *}$ & 4.08 & 1.03 \\
7 & $.909^{* *}$ & $12.33^{* *}$ & 4.17 & .95 \\
8 & $.902^{* *}$ & $12.38^{* *}$ & 4.08 & .90 \\
9 & $.935^{* *}$ & $15.25^{* *}$ & 4.00 & .97 \\
10 & $.909^{* *}$ & $14.69^{* *}$ & 3.91 & .92 \\
11 & $.894^{* *}$ & $14.17^{* *}$ & 3.95 & .95 \\
13 & $.767^{* *}$ & $17.02^{* *}$ & 3.21 & 1.03 \\
14 & $.755^{* *}$ & $14.01^{* *}$ & 2.63 & 1.07 \\
15 & $.691^{* *}$ & $10.21^{* *}$ & 2.81 & 1.08 \\
16 & $.908^{* *}$ & $12.65^{* *}$ & 2.02 & 1.18 \\
17 & $.916^{* *}$ & $13.27^{* *}$ & 2.39 & 1.19 \\
18 & $.895^{* *}$ & $11.23^{* *}$ & 2.20 & 1.10 \\
19 & $.836^{* *}$ & $12.34^{* *}$ & 2.42 & 1.19 \\
20 & $.908^{* *}$ & $15.62^{* *}$ & 2.46 & 1.18 \\
21 & $.841^{* *}$ & $14.86^{* *}$ & 2.11 & 1.13 \\
22 & $.847^{* *}$ & $13.84^{* *}$ & 1.82 & 1.07 \\
\hline
\end{tabular}

**: $\mathrm{p}<0,01$

\section{Güvenirlik}

Güvenirlik, bir ölçme aracının duyarlı (tesadüfi hatalardan arınıklık) ve ölçmeden ölçmeye tutarlı sonuçlar verebilmesi özelliğidir (Tezbaşaran, 1996) Bu çalışmada ölçeğin geneli ve alt boyutlarına yönelik Cronbach Alpha İç Tutarlık Katsayısı hesaplanmıştır. Cronbach Alpha Güvenirlik analizinde Alpha değerinin en az 0.70 olması gerektiği (Anderson, 1988) ifade edilmektedir.

Tablo 4. Güvenirlik tablosu

\begin{tabular}{llc}
\hline \multirow{2}{*}{ Destekleyici Antrenör Davranışları } & Boyutlar & Cronbach Alpha \\
& Özerklik Destekleme & 0.80 \\
& Yeterlilik Desteği & 0.88 \\
& İlişki Desteği & 0.93 \\
\hline \multirow{2}{*}{ Engelleyici Antrenör Davranışları } & Özerkliği Engelleme & 0.73 \\
& Yeterlilik Engelleme & 0.89 \\
& İlişki Engelleme & 0.88 \\
\hline
\end{tabular}


Tablo 4' de görüldüğg̈ gibi güvenirlik analizi sonucunda ölçme aracının Cronbach Alpha güvenirlik değerleri “Özerklik Destekleme " alt boyutunda 0.80, "Yeterlilik Desteği”" alt boyutunda 0.88, "İlişki Desteği”" alt boyutunda 0,93, "Özerkliği Engelleme” alt boyutunda 0.73 , "Yeterlilik Engelleme" alt boyutunda 0.89 ve "İlişki Engelleme" alt boyutunda ise 0,88 olarak tespit edilmiştir. Bu sonuçlar ölçme aracının yüksek düzeyde güvenilir ölçümler yapabileceği anlamina gelmektedir.

\section{TARTIŞMA ve SONUÇ}

$\mathrm{Bu}$ araştırmada “Antrenör Kişilerarası Davranış Tarzı Ölçeği”nin Türk kültürüne uyarlanması amaçlanmıştır.

Ölçme aracının geçerliği için dil geçerliği ve yapı geçerliği incelenmiş, güvenirliği için ise, Cronbach Alpha iç tutarlılık kat sayısına bakılmıştır. Ölçme aracının yapı geçerliğini değerlendirmek için doğrulayıcı faktör analizi (DFA) kullanılmıştır. DFA sonucunda ölçme aracının 12. maddesi için anlamlı $t$ değeri elde edilememiş ve bu maddeye ait hata varyansının da (0.86) yüksek olduğu belirlenmiştir. Ayrıca 12. maddenin ilgili boyuttaki faktör yükünün (0.26) düşük olması nedeniyle ölçme aracından çıkarılmasına karar verilmiştir. 12. maddenin çıkarılmasının ardından DFA tekrarlanılmıştır.

21 madde üzerinden tekrarlanan DFA sonucunda, örneklem grubundan elde edilen veriler ile 6 boyuttan oluşan faktör yapısının uyumlu olduğu tespit edilmiştir. Madde çıarılmadan önceki ve madde çıkarıldıktan sonraki uyum indekslerine ait değerler incelendiğinde; $\mathrm{X}^{2} / \mathrm{sd}$, RMSEA, PGFI, PNFI, GFI, CFI ve AGFI'ye ilişkin değerlerde iyileşme meydana geldiği görülmektedir. Uyum indekslerine ait değerlerin tamamı değerlendirildiğinde, ölçeğin Türkçe formundan elde edilen veriler arasındaki ilişkilerin kuramsal yapı tarafından açıklandığı söylenebilir. Madde analizleri kapsamında gerçekleştirilen madde toplam test korelasyonu değerlerinin uygun olduğu belirlenmiş̧ir. Maddelerin ayırt ediciliğine yönelik analizler de, her bir maddenin ölçülmesi istenen özelliğe yüksek düzeyde sahip olduğu varsayılan kişiler ile özelliğe düşük düzeyde sahip olduğu varsayılan kişileri ayırt etmede başarılı olduğu sonucuna varılmıştır. Ölçme aracının alt boyutlarına ilişkin güvenirlik değerleri incelendiğinde, Özerklik Destekleme, 0.80; Yeterlilik Desteği, 0.88; İlişki Desteği, 0.93; Özerkliği Engelleme, 0,73; Yeterlilik Engelleme, 0.89; İlişki Engelleme, 0.88 olduğu belirlenmiştir. Elde edilen güvenirlik değerlerinin, orijinal ölçeğin 
Esentürk, O.K. (2019). Antrenör kişilerarası davranış tarzı ölçeği: geçerlik-güvenirlik çalışması. CBÜ Beden Eğitimi ve Spor Bilimleri Dergisi, 14 (2), 304-314.

geliştirilmesi çalışmasında ve ölçekten yararlanılan diğer çalışmalarda elde edilen iç tutarlılık katsayıları ile uyumlu olduğu söylenebilir.

\section{KAYNAKLAR}

Adie, J. W., Duda, J. L., \& Ntoumanis, N. (2012). Perceived coach-autonomy support, basic need satisfaction and the well and ill-being of elite youth soccer players: Alongitudinal investigation. Psychology of Sportand Exercise, 13, 51-59.

Anderson L. W. (1988). Attitudes and their measurement. InJ. P. Keeves (Ed.), Educational research, methodology and measurement: An international hand book (pp. 885-895). New York: Pergamon Press.

Balaguer, I.,González, L., Fabra, P., Castillo, I., Mercé, J., \& Duda, J. L. (2012). Coaches’ interpersonal style, basic psychological needs and thewell- and ill-being of young soccerplayers: A longitudinalanalysis. Journal of Sports Sciences, 30(15), 1619-1629.

Brown, T. A. (2014). Confirmatory factor analysis for applied research. Guilford Publications. ContemporaryEducational Psychology, 25(1), 54-67.

Buyukozturk, S.,Akgun, O., Kahveci, O., \& Demirel, F. (2004). Güdülenme ve öğrenme stratejileri ölçeğinin türkçe formunun geçerlik ve güvenirlik çalışması. Kuram ve Uygulamada Eğitim Bilimleri, 4(2), 207-239.

Curran, T.,Hill, A. P., \& Niemiec, C. P. (2013). A conditional process model of children's behavioral engagement and behavioral disaffection in sport based on self determination theory. Journal of Sport and ExercisePsychology, 35, 30 43. doi:10.1123/jsep.35.1.30.

Curran, T.,Hill, A. P., Hall, H. K., \& Jowett, G. E. (2014). Perceived coach behaviors and athletes' engagement and disaffection in youth sport: The mediating role of the psychological needs. International Journal of Sport Psychology, 45(6), 559-580.

Çakmak, E. K.,Çebi, A., \& Kan, A. (2014). E-öğrenme ortamlarına yönelik “sosyal bulunuşluk ölçeği” geliştirme çalışması. Kuram ve Uygulamada Ë̆itim Bilimleri, 14(2), 755-768.

Çokluk, Ö., Şekercioğlu, G., \& Büyüköztürk, Ş. (2010). Çok değişkenli istatistik SPSS ve LISREL uygulamaları (Birinci bask1). Ankara: Pegem Akademi Yayınları.

Deci, E. L.;Ryan, R. M. (1985). Intrinsic motivation and self-determination in human behavior. New York, NY: PlenumPress

Erkuş, A. (2014). Psikolojide ölçme ve ölçek geliştirme-I: Temel kavramlar ve işlemler (2. Baskı). Ankara: Pegem Yayınları.

Fraser-Thomas, J., \& Côté, J. (2009). Understanding adolescents' positive and negative developmental experiences in sport. The sport psychologist, 23(1), 3-23.

Gould, D.,Tuffey, S., Udry, E., \&Loehr, J. (1996). Burnout in competitive junior tennis players: A quantitative psychological assessment. The sport psychologist, 10(4), 322-340.

Hooper, D.,Coughlan, J., \&Mullen, M. (2008). Structural equation modelling: Guidelines for determining model fit. Electronic Journal on Business Research Methods 6(1), 53-60.

Jöreskog, K. G.,\&Sörbom, D. (1993). LISREL 8: Structural equation modeling with the simplis command language. Lincolnwood: Scientific Software International, Inc.

Karasar, N. (2014). Scientific Research Method: Concepts Principles Techniques. Ankara: Nobel Academy Publishing.

Kline, R. B. (2005). Methodology in the social sciences. Principles and practice of structural equation modeling (2nd ed.). Guilford Press. 
Esentürk, O.K. (2019). Antrenör kişilerarası davranış tarzı ölçeği: geçerlik-güvenirlik çalışması. $C B \ddot{U}$ Beden Eğitimi ve Spor Bilimleri Dergisi, 14 (2), 304-314.

Pulido, J. J.,Sánchez-Oliva, D., Leo, F. M., Matos, S., \& García-Calvo, T. (2017). Effects of an interpersonal style intervention for coaches on young soccer players' motivational processes. Journal of human kinetics, 59(1), 107-120.

Reeve, J. (2009). Why teachers adopt a controlling motivating style toward student and how they can become more autonomy supportive. Educational psychologist, 44(3), 159-175.

Ryan, R. M.,\& Deci, E. L. (2000). Self-determination theory and the facilitation of intrinsic motivation, social developmentand wellbeing. American Psychologist, 55, 68-78. doi:10.1037/0003-066X.55.1.68.

Schermelleh-Engel, K., Moosbrugger, H., \& Müller, H. (2003). Evaluatingthe fit of structural equation models: Tests of significance and descriptive goodness-of-fit measures. Methods of psychological research online, 8(2), 23-74.

Schumacher, R. E.,\&Lomax, R. G. (1996). A beginner'sguideto SEM. New Jersey: Mahwah.

Seçer, İ. (2015). SPSS ve LISREL ile Pratik Veri Analizi, (2. Baskı). Ankara: Anı Yayıncılık.

Sümer, N. (2000). Yapısal eşitlik modelleri: Temel kavramlar ve örnek uygulamalar. Türk Psikoloji Yazıları, 3(6), 49-74.

Tabachnick, B. G.,\& Fidell, L. S. (2007). Multivariate analysis of variance and covariance. Using multivariate statistics. Boston: Allynand Bacon.

Tezbaşaran, A. (1996). Likert tipi ölçek geliştirme kılavuzu. Ankara: Psikologlar Derneği Yayınları.

Thompson, B. (2004). Exploratory and confirmatory factor analysis: Understanding concepts and applications. American Psychological Association. 